\title{
Helicobacter pylori gastritis and primary gastric non-Hodgkin's lymphomas
}

\author{
S Eidt, $M$ Stolte, $R$ Fischer
}

\begin{abstract}
Aims-To evaluate further the relation between gastric malignant lymphoma of the mucosa associated lymphoid tissue (MALT) and Helicobacter pylori.

Methods-One hundred and sixty two surgical specimens of MALT lymphoma were retrospectively investigated to determine tumour type and inflammatory patterns. In 121 cases biopsy specimens obtained before surgery were available and stained with haematoxylin and eosin, periodic acid Schiff, Giemsa and Warthin-Starry stains.

Results-Residual lymphoid follicles were found less often in high grade malignant than in low grade malignant MALT lymphomas. Chronic active gastritis was shown within the mucosa at some distance from the tumours in 143 of 146 specimens. In all the cases for which biopsy specimens could be evaluated, colonisation of the mucosa by $H$ pylori had occurred. Lymphoid follicles and lymphoid aggregates were detected in $82.7 \%$ of the antral, and in $85 \%$ of the body mucosa specimens.

Conclusions-These data support the hypothesis that $H$ pylori has an important role in the development of MALT lymphomas. Furthermore, the chronic inflammation preceding malignant transformation might enhance the probability of malignant transformation via chronic stimulation of the lymphoid tissue. This might in part indicate why MALT lymphomas occur most often in the stomach.
\end{abstract}

(F Clin Pathol 1994;47:436-439)

One of the most exciting current developments in gastroenterology is the discovery that Helicobacter pylori has a decisive role in gastroduodenal disease. ${ }^{1-3}$ Recently, several groups have published data showing a correlation between $H$ pylori and gastric carcinomas. ${ }^{4-6}$ Wotherspoon et al were the first to investigate the presence of $H$ pylori in larger numbers of gastric lymphomas of the mucosa associated lymphoid tissue (MALT lymphomas): in 92\% of cases $H$ pylori was indeed detected. ${ }^{7}$ On the basis of earlier observations that the prevalence of lymphoid follicles correlated significantly with the detection of $H$ pylori, ${ }^{89}$ they suggested that $H$ pylori might trigger the acquisition of MALT in the gastric mucosa which usually contains only a few $\mathrm{T}$ lymphocytes. ${ }^{10}$ In the light of these findings $H$ pylori and the subsequent inflammatory response might be prerequisites for the development of a MALT lymphoma in the stomach. Further support for this hypothesis was provided by data published by Doglioni and coworkers which showed that the high prevalence of gastric MALT lymphoma correlated closely with a high prevalence of $H$ pylori infection in a town in northern Italy. ${ }^{11}$ If the suggested route to MALT through $H$ pylori infection to the malignant transformation holds true, then not only $H$ pylori but an inflammatory response to $H$ pylori infection should be evident in almost all cases of MALT lymphoma as well. To elucidate further this association we retrospectively investigated 162 cases of gastric resection specimens for gastric lymphoma.

\section{Methods}

One hundred and sixty six surgical specimens of gastric lymphoma (56 gastrectomies, 95 arboral resections, nine local excisions, six resections of the gastric remnant were examined at the Institute of Pathology, Bayreuth, over a period of 11 years. They were fixed in $10 \%$ formalin, embedded in paraffin wax and routinely stained with haematoxylin and eosin periodic acid Schiff and Giemsa. The lymphomas were classified according to the proposal of the European Lymphoma Study Group. ${ }^{12}$ Only B cell lymphomas of MALT type were included in this study. Two plasmocytomas and two $\mathrm{T}$ cell lymphomas were excluded, reducing the number of cases investigated to 162 .

The phenotypic evaluation of lymphomas was done using monoclonal antibodies recognising formalin fixation resistant antigens (L26, UCHL1, MT1, all from Dako) and a subsequent peroxidase-antiperoxidase method. The high grade malignant MALT lymphomas were divided into those with and without a low grade component. Furthermore, the depth of infiltration into the gastric wall was evaluated using the International Union against Cancer classification of gastric cancer (table 1).13 Clinical staging of lymphoma was also carried out in all patients using abdominal computed tomograms or ultrasonography, liver and bone marrow biopsies

\begin{tabular}{ll} 
Table 1 & UICC classification of gastric carcinoma \\
\hline pT1 & Tumour restricted to mucosa and submucosa \\
pT2 & $\begin{array}{l}\text { Tumour infiltrating beyond the submucosa into } \\
\text { the muscularis propria and the subserosal layer }\end{array}$ \\
pT3 & $\begin{array}{l}\text { Tumour penetrating the serosa } \\
\text { pT4 }\end{array}$ \\
$\begin{array}{l}\text { Tumour continously infiltrating other organs } \\
\text { (liver, spleen) }\end{array}$ \\
\hline
\end{tabular}

Correspondence to: Professor M Stolte, Institute of Pathology, Klinikum Bayreuth, 95445 Bayreuth Accepted for publication 3 November 1993 
Table 2 Modified Ann Arbor classification for extranodal lymphomas

\begin{tabular}{ll}
\hline$E I$ & $\begin{array}{l}\text { Lymphoma restricted to gastrointestinal tract on one } \\
\text { side of the diaphragm } \\
\text { E I Infiltration limited to mucosa and submucosa } \\
\text { E I } I_{2} \text { Lymphoma extending beyond submucosa } \\
\text { Lymphoma additionally infiltrating lymph nodes on } \\
\text { the same side of diaphragm }\end{array}$ \\
E II Infiltration of regionary lymph nodes \\
E III II Infiltration of lymph nodes beyond regional $_{\text {Lymphoma infiltrating gastrointestinal tract and/or }}$ \\
E IV lymph nodes on both sides of the diaphragm \\
Localised infiltration of gastrointestinal site with or \\
without infiltration of associated lymph nodes together \\
with diffuse or disseminated involvement of extra- \\
gastrointestinal organs.
\end{tabular}

with subsequent classification according to the modified Ann Arbor scheme ${ }^{14}{ }^{15}$ (table 2), and only tumours in which the largest tumour mass was located in the stomach. The presence of non-neoplastic reactive lymphoid follicles within the tumours was registered.

In 146 cases it was also possible to evaluate the gastric mucosa at least $4 \mathrm{~cm}$ away from the tumours for infiltration of the lamina propria with lymphocytes, plasma cells, and neutrophilic polymorphs as well as intestinal metaplasia. The prevalence of lymphoid aggregates and follicles was also registered. The latter were diagnosed when germinal centres could be detected. $H$ pylori gastritis was diagnosed when a lymphoplasmacellular infiltrate was combined with neutrophilic polymorphs concentrated around the neck region with infiltration of gastric glands. In accordance with these criteria, all cases of chronic active gastritis were classified as $H$ pylori gastritis. Because of the influence of delayed fixation on the detection of $H$ pylori (M Stolte, unpublished observations) we also investigated endoscopic biopsy specimens taken three months or less before the surgical procedure for colonisation of the gastric mucosa with $H$ pylori; such biopsy specimens were available in 121 cases. $H$ pylori was detected using the Warthin-Starry stain. Lymphocytic and reactive gastritis were diagnosed according to the criteria given before. ${ }^{16} 17$

Statistical evaluation was done using the $\chi^{2}$ test.

\section{Results}

The mean age of the patients (74 men, 88 women) was $62 \cdot 2$ years, with a standard deviation of $13 \cdot 1$ years and a range from 20 to 92 years. The types of lymphomas detected, together with their prevalences, are shown in table 3. The staging of the tumours according to the Ann Arbor classification showed that most were only locally infiltrating: $E I_{1}$ in 72 $(44 \cdot 4 \%)$ cases and $E I_{2}$ in $33(20.4 \%)$ cases. Only in $41(25.3 \%)$ patients was an infiltration of regional lymph nodes detected $\left(\mathrm{E} \mathrm{II}_{1}\right)$,

Table 3 Histological classification of gastric lymphomas $(n=162)$ and their prevalence (MALT mucosa associated lymphoid tissue

\begin{tabular}{ll}
\hline Low grade malignant MALT lymphomas & 91 \\
High grade malignant MALT lymphomas & \\
with low grade component & 21 \\
without low grade component & 50 \\
\hline
\end{tabular}

Table 4 Breakdown of depth of tumorous infiltration of gastric wall by degree of malignancy $(n=162)$

\begin{tabular}{lrrr}
\hline & \multicolumn{1}{l}{ Low } & Low + high & \multicolumn{1}{l}{ High } \\
\hline pT1 & $66(74 \cdot 2 \%)$ & $10(11 \cdot 2 \%)$ & $13(14 \cdot 6 \%)$ \\
pT2 & $18(45 \cdot 0 \%)$ & $6(15 \cdot 0 \%)$ & $16(40 \cdot 0 \%)$ \\
pT3 & $6(22 \cdot 2 \%)$ & $5(18 \cdot 5 \%)$ & $16(59 \cdot 3 \%)$ \\
pT4 & $1(16 \cdot 7 \%)$ & & $5(83 \cdot 3 \%)$ \\
\hline p<0.001. & & &
\end{tabular}

and in four $(2 \cdot 5 \%)$ cases had infiltrated distant lymph nodes. Liver or spleen metastases were found in three $(1.9 \%)$ cases and bone marrow infiltration in two $(1 \cdot 2 \%)$. In seven $(4 \cdot 3 \%)$ patients in whom only a local excision was performed no classification was possible. The correlation between the depth of infiltration and the grade of the lymphomas (table 4) reached significance $(p<0.001)$. The largest tumour diameters are shown in table 5 . The types of gastritis detected in the mucosa located at a distance from the tumours are listed in table 6 . In all the cases of chronic active gastritis the biopsy specimens taken before surgery showed $H$ pylori colonisation of the gastric mucosa. A correlation between largest diameters, grade, or depth of infiltration could not be demonstrated. Reactive non-neoplastic lymphoid follicles were found within the tumours in $62.0 \%$ of cases. An analysis of their correlation with degree of malignancy and with depth of infiltration reached significance in the case of the former $(p<0.001)$ (table 7). In the latter, however, owing to the small number of cases in the pT4 group, statistical analysis was possible only by pooling pT3 and pT4 lesions $(\mathrm{p}<0.05)$ (table 8). The prevalence of lymphoid follicles and lymphoid aggregates in the antral and

Table 5 Largest tumour diameters $(n=147)$

\begin{tabular}{lllll}
\hline$\leqslant 20 \mathrm{~mm}$ & $<40$ & $<60$ & $<80$ & $>80$ \\
\hline $22(15 \cdot 0 \%)$ & $41(27 \cdot 9 \%)$ & $37(25 \cdot 1 \%)$ & $25(17 \cdot 0 \%)$ & $22(15 \cdot 0 \%)$ \\
\hline
\end{tabular}

Table 6 Types of gastritis in gastric lymphomas of MALT $(n=162)$

\begin{tabular}{lc}
\hline Insufficient material & 16 \\
Chronic active gastritis & $143(97 \cdot 9 \%)$ \\
Lymphocytic gastritis & $1(0 \cdot 7 \%)$ \\
Reactive gastritis & $1(0 \cdot 7 \%)$ \\
No gastritis & $1(0 \cdot 7 \%)$ \\
\hline
\end{tabular}

Table 7 Prevalence of lymphoid follicles (LF) within gastric lymphomas broken down by degree of malignancy

\begin{tabular}{ll}
\hline Low & $70(78 \cdot 7 \%)$ \\
Low + high & $13(61 \cdot 9 \%)$ \\
High & $12(24.0 \%)$ \\
\hline$p<0.001$. &
\end{tabular}

Table 8 Prevalence of lymphoid follicles (LF) within gastric lymphomas broken down by depth of malignant infiltration

\begin{tabular}{lr}
\hline pT1 & $60(69 \cdot 0 \%)$ \\
pT2 & $20(51.3 \%)$ \\
pT3 & $12(44 \cdot 4 \%)$ \\
pT4 & $2(33.3 \%)$ \\
\hline p $<0.05$ (pT3 together with pT4). &
\end{tabular}


Table 9 Prevalence of lymphoid follicles (LF), lymphoid aggregates (LA) and their combination (LF/LA) in gastric mucosa away from the lymphomas

\begin{tabular}{lllll}
\hline & $L A+$ & $L F+$ & $L F / L A+$ & Total \\
\hline Antral mucosa $(\mathrm{n}=139)$ & 49 & 48 & 18 & $115(82 \cdot 7 \%)$ \\
Oxyntic mucosa $(\mathrm{n}=140)$ & 60 & 43 & 16 & $119(85.0 \%)$ \\
\hline
\end{tabular}

Table 10 Prevalence of intestinal metaplasia (IM) in gastric mucosa at a distance from the lymphomas

\begin{tabular}{ll}
\hline Antral mucosa $(n=139)$ & $54(38 \cdot 8 \%)$ \\
Oxyntic mucosa $(n=140)$ & $24(17 \cdot 1 \%)$ \\
\hline
\end{tabular}

body mucosa is shown in table 9 . The distribution of intestinal metaplasia of the gastric mucosa located at a distance from the lymphomas is shown in table 10. Significant correlations with the degree of malignancy or the depth of infiltration could not be shown.

\section{Discussion}

A MALT system as exemplified in Peyer's patches is not present in the normal gastric mucosa. ${ }^{10}$ Following infection with $H$ pylori, MALT is acquired..$^{7-9}$ Further evidence for this sequence of events is provided by the results of eradication studies. After successful eradication of $H$ pylori, the density of the lymphoplasmacellular infiltration in the lamina propria decreased substantially ${ }^{18}$ and lymphoid aggregates and lymphoid follicles, present before were no longer detectable in control biopsy specimens (unpublished own observations). More support for the hypothesis that $H$ pylori plays an important part in the genesis of MALT lymphoma comes from recent serological, epidemiological, and histopathological research. Parsonett et al reported in 1991 that in patients with gastric lymphomas antibodies against $H$ pylori were present in $90.9 \%$ compared with $63.6 \%$ of matched controls. ${ }^{6}$ They only investigated 11 patients. Wotherspoon et al histologically evaluated 110 MALT lymphomas of the stomach in both biopsy and surgical specimens, looking for the presence of $H$ pylori, and found the organisms in $92 \%$ of cases. ${ }^{7}$ This prevalence of $H$ pylori was significantly higher than that reported for non-ulcer dyspepsia (50-60\%). ${ }^{19}$ An analysis of epidemiological data published by Doglioni et al showed a high prevalence of primary gastric lymphoma in a town in northern Italy, correlated with a high prevalence of $H$ pylori infection. Similarly, a low prevalence of gastric lymphoma was observed in a number of British towns with a low prevalence of $H$ pylori. ${ }^{11}$

The data presented here are based exclusively on findings in surgical specimens, and for the first time the gastritis associated with the lymphomas has been investigated as well. An extremely high prevalence of chronic active gastritis with features typical of $H$ pylori aetiology was demonstrated in gastric MALT lymphoma $(97 \cdot 7 \%)$, compared with the results of a study of 5000 gastric biopsy specimens of various forms of gastritis at our insti- tution. Only $71 \cdot 8 \%$ of cases showed $H$ pylori gastritis. ${ }^{20}$ The results of epidemiological analyses of the prevalence of HP in a control population indicated a prevalence ranging from $61 \%$ to $76 \% .^{5-6}$ Biopsy specimens taken before surgery confirmed the assumed $H$ pylori aetiology in our cases of chronic active gastritis. In addition, one case each of lymphocytic and reactive gastritis were found (table 6). Lymphocytic gastritis is mostly triggered by $H$ pylori infection and for the most part represents a special type of reaction to $H$ pylori so this case might be included in the category of gastritis induced by $H$ pylori. ${ }^{21}$ Almost all MALT lymphomas therefore, show an inflammatory infiltrate in the gastric mucosa most probably caused by $H$ pylori.

Another point hinting at the importance of $H$ pylori is the enormous prevalence of lymphoid follicles and lymphoid aggregates and intestinal metaplasia found in the gastric mucosa at a distance from the tumour (tables 9 and 10). Comparing these data with the published prevalences for benign gastroduodenal disease, in particular in the body mucosa, a substantial increase in lymphoid aggregates, lymphoid follicles, and intestinal metaplasia was noted in MALT lymphoma. ${ }^{22} 23$ Intestinal metaplasia has been shown to be more prevalent in older patients, and probably represents longstanding $H$ pylori gastritis. ${ }^{23}{ }^{24}$ All in all, an analysis of the gastric mucosa showed, in almost all cases of MALT lymphoma, evidence for longstanding $\mathrm{HP}$ gastritis with acquisition of MALT. Our data thus support the hypothesis of Wotherspoon et al that $H$ pylori has a crucial role in the evolution of gastric lymphomas of the MALT type by triggering the acquisition of MALT in the stomach mucosa. ${ }^{7}$ The two cases of MALT lymphomas in which no $H$ pylori induced inflammatory reaction was detected do pose a problem in that respect. It is, however, possible to speculate that in these cases $H$ pylori had been eradicated after a malignant transformation of the acquired MALT.

It might be argued, however, that $H$ pylori gastritis develops secondary to MALT lymphoma. In contrast to patients with chronic gastritis, in whom the prevalence of $H$ pylori increases with increasing age, we found no increased prevalence of $H$ pylori in older patients. ${ }^{25}$ Furthermore, no correlation of the $H$ pylori colonisation with depth of infiltration, grade, or largest diameters of the lymphomas was to be found-as ought to be the case in secondary colonisation of MALT lymphomas.

With respect to the malignant transformation of MALT to MALT lymphoma, apart from the relatively safe assumption that MALT lymphomas develop from parafollicular centrocytoid-like cells of the parafollicular region, ${ }^{26}$ the exact mechanisms are unknown. The continuing stimulation of the local immune system following $H$ pylori infection might enhance the probability of its malignant transformation, especially as the infection persists throughout the patient's life if left to its natural course, as can be deduced from age distribution prevalence. ${ }^{25}$ That chronic 
infection can trigger lymphoproliferation has been shown in Epstein-Barr infection. ${ }^{27} 28$ If the assumption is correct that $H$ pylori infection is not merely the basis for, but actively contributes to, the aetiology of gastric lymphoma, then in view of the far greater prevalence of $H$ pylori infection than of MALT lymphoma, additional factors must operate. These might include peculiarities of the $H$ pylori strain involved: the high prevalence of lymphoid follicles and lymphoid aggregates might be interpreted as features of a possible high immunogeneity. Furthermore, exogenic-for example, dietary factors, virus infections, or disorders of immune regulation-have to be taken into consideration. The chronic inflammation caused by $H$ pylori could be an important part of the answer to the question why the stomach has the highest prevalence of MALT lymphomas, ${ }^{29-31}$ although in the normal stomach only a few lymphocytes are found in the lamina propria and epithelium. ${ }^{10}$ Studies aimed at analysing the additional factors mentioned and estimating the possible benefit of eradication of $H$ pylori are in progress.

Although many questions concerning MALT lymphomas remain to be elucidated, we conclude that our results, together with the reported data, strongly support the hypothesis that $H$ pylori gastritis, by leading to the acquisition of MALT, is a prerequisite for the development of a MALT lymphoma in the stomach in almost all cases. Whether $H$ pylori and the inflammatory response also actively contribute to the formation of lymphomas in the stomach has yet to be determined.

We thank Professor K Lennert, head of the Lymph Node Register of the German Society of Pathology, and Professor K Müller-Hermelink, director of the Pathological Department of
the University of Wurzburg, for additionally reviewing our surthe University of Wurzburg, for additionally reviewing our sur-
gical specimens and carrying out a histochemical diagnostic gical specimens and carryin
evaluation in some of them.

1 Marshall BJ, Goodwin CS, Warren JR, Murray R, Blincow ED, Blackbourn SJ, et al. Prospective double blind trial of duodenal ulcer relapse after eradicatio

2 Fiocca L, Solcia E, Santoro B. Duodenal ulcer relapse after eradication of Helicobacter pylori. Lancet 1991; 337:1614.

3 Graham DY, Lew GM, Kleine PD, Evans DG, Evans DJ, Saeed ZA, et al. Results of treatment of Helicobacter pylori infection on the recurrence of gastric or duodenal ulcers: A randomized single-blind, single center study. Gastroenterology 1991;100:A 431.

4 Forman D, Newell DG, Fullerton F, Yarnell JWG, Stacey AR, Wald N. et al. Association between infection with Helicobacter pylori and risk of gastric cancer: evidence Helicobacter pylori and risk of gastric cancer: evidence
from a prospective investigation. $\mathrm{Br} \mathrm{Med} \mathcal{J} 1991 ; 302$ : from a

5 Nomura A, Stemmermann GN, Chyou PH, Kato I, PerezPerez GI, Blaser MJ. Helicobacter pylori infection and gastric carcinoma among Japanese-Americans in Hawaii. N Engl f Med 1991;325:1132-6.

6 Parsonett J, Vandersteen D, Goates J, Sibley RK, Prittkin J, Chang Y. Helicobacter pylori infection in intestinal- and diffuse-type gastric adenocarcinoma. $¥ N C I$ 1991;83: diffuse-typ

7 Wotherspoon AC, Ortiz-Hidalgo C, Falzon MR, Isaacson PG. Helicobacter pylori-associated gastritis and primary B-cell gastric lymphoma. Lancet 1991;338:1175-6.

8 Wyatt JI, Rathbone BJ. Immune response of the gastric mucosa to Campylobacter pylori. Scand $\mathcal{f}$ Gastroenterol 1988;23(suppl 142):44-9.

9 Stolte M, Eidt S. Lymphoid follicles of the antral mucosa: immune reaction to Campylobacter pylori? $f$ Clin Pathol 1989;42:1269-71.

10 Kirchner T, Melber A, Fischbach W, Heilmann KL, Müller-Hermelink HK. Immunohistochemical patterns of the local immune response in Helicobacter pylori gasof the local immune response in Helicobacter pylori gas-
tritis. In: Malfertheimer P, Dischuneit H, eds. tritis. In: Malfertheimer $\mathrm{P}$, Dischuneit $\mathrm{H}$, eds. Springer, 1990:213-22.

11 Doglioni C, Wotherspoon AC, Moschini A, De Boni M, Isaacson PG. High incidence of primary gastric lymphoma in north eastern Italy. Lancet 1992;339:834-5.

12 Isaacson PG, Spencer J, Wright DH. Classifying primary gut lymphomas. Lancet 1988;330:1148-9.

13 Hermanek P, Sobin LH eds. TNM-Klassifikation maligner Tumoren. 4th edition. Berlin: Springer, 1987.

14 Musshoff $K$, Schmidt-Vollmer $H$. Prognosis of nonHodgkin's lymphomas with special emphasis on staging Hodgkin's lymphomas with special emphasis
classification. Z Krebsforschung 1975;83:323-8.

15 Radaskiewics Th, Dragosics B, Bauer P. Gastrointestina malignant lymphomas of the mucosa-associated lymphoid tissue: factors relevant to prognosis. Gastroenterology 1992;102:1628-38.

16 Haot J, Hamuchi L, Walley L, Mainguet P. Lymphocytic gastritis: a newly described entity. A retrospective endoscopic and histological study. Gut 1988;29:1258-64.

17 Dixon MF, O'Connor HJ, Axon ATR, King RFJ, Johnston D. Reflux gastritis: a distinct histopathological entity? 7 Clin Pathol 1986;39:524-30.

18 Stolte M. Helicobacter pylori gastritis and gastric MALTlymphoma. Lancet 1992;339:745-6.

19 Shallcross TM, Rathbone BJ, Heatley RG. Campylobacter pylori and non-ulcer dyspepsia. In: Rathbone BJ Heatley RV, eds. Campylobacter pylori and gastroduodenal disease. Oxford: Blackwell Scientific Publications, 1989: 155-6.

20 Stolte M, Bethke B, Ritter M, Lauer E, Eidt H. Praxis der Gastritis-Klassifikation. Endoskopie heute 1990;4:228-30.

21 Crabtree JE, Mahony MJ, Taylor JD, Heatley RV Littlewood JM, Tompkins DS. Immune responses to Helicobacter pylori in children with recurrent abdominal pain. 7 Clin Pathol 1991;44:768-71.

22 Eidt $S$, Stolte $M$. Frequency distribution of lymphoid follicles and lymphoid aggregates in Helicobacter pylori gas-
tritis in antral and body mucosa of the stomach. Irish $f$ tritis in antral and body mucosa

23 Eidt S, Stolte M. Antral intestinal metaplasia in Helicobacter pylori gastritis. Digestion 1994;55:13-18.

24 Craanen ME, Decker W, Blok P, Ferweda J, Tytgat GNJ. Intestinal metaplasia and Helicobacter pylori: an endoscopic-bioptic study of the gastric antrum. Gut 1992;33:6-10.

25 Stolte M, Eidt S, Ohnsmann A. Differences in the Helicobacter pylori associated gastritis in the antrum and body of the stomach. $Z$ Gastroenterol 1990;28. 229-33.

26 Isaacson PG, Wotherspoon AC, Diss T, Pan L. Follicular colonization in B-Cell lymphoma of mucosa-associated colonization in B-Cell lymphoma of mucosa-associate
lymphoid tissue. Am $f$ Surg Pathol 1991;15:819-28.

27 Krueger GRF, Papdakis Th, Schaefer HJ. Persistent active Epstein-Barr virus infection and atypical lymphoproliferation. Am $\mathcal{F}$ Surg Pathol 1987;11:972-81.

28 Puertilo DT, Tatsumi E, Manolov G, Manolova Y, Harada S, Lipscomb H, et al. Epstein-Barr virus as an etiological agent in the pathogenesis of lymphoproliferative and aproliferative diseases in immune deficien patients. Int Rev Exp Pathol 1985;27:114-82.

29 Freeman C, Berg JW, Cutler SJ. Occurrence and prognosis of extranodal lymphomas. Cancer 1972;29:252-60.

30 Herrman R, Panahon AM, Barcos MP, Walsh D, Stutzman L. Gastrointestinal involvement in nonStutzman L. Gastrointestinal involvement in

31 Otter R, Bieger R, Kluin PhM, Hermans J, Willemze R Primary gastrointestinal lymphoma in a populationbased registry. $\mathrm{Br} \mathcal{F}$ Cancer 1989;60:745-50. 